\title{
Fields of Tension in a Boundary-Crossing World: Towards a Democratic Organization of the Self
}

\author{
Hubert J. M. Hermans ${ }^{1}$ - Agnieszka Konopka ${ }^{2}$. \\ Annerieke Oosterwegel ${ }^{3} \cdot$ Peter Zomer $^{4}$
}

\begin{abstract}
In their study of the relationship between self and society, scientists have proposed taking society as a metaphor for understanding the dynamics of the self, such as the analogy between the self and the functioning of a totalitarian state or the analogy between the self and the functioning of a bureaucratic organization. In addition to these models, the present article proposes a democratic society as a metaphor for understanding the workings of a dialogical self in a globalizing, boundary-crossing world. The article follows four steps. In the first step the self is depicted as extended to the social and societal environment and made up of fields of tension in which a multiplicity of self-positions are involved in processes of positioning and counter-positioning and in relationships of social power. In the second step, the fertility of the democratic metaphor is demonstrated by referring to theory and research from three identity perspectives: multicultural, multiracial, and transgender. In the fields of tension emerging between the multiplicity of self-positions, new, hybrid, and mixed identities have a chance to emerge as adaptive responses to the limitations of existing societal structures. In the third step, we place the democratic self in a broader societal context by linking three levels of inclusiveness, proposed by Self-Categorization Theory (personal, social, and human) to recent conceptions of a cosmopolitan democracy. In the fourth and final step, a model is presented which allows the formulation of a series of specific research questions for future studies of a democratically organized self.
\end{abstract}

Hubert J. M. Hermans

hhermans@psych.ru.nl

1 Radboud University of Nijmegen, Gagelveld 34, Milsbeek, The Netherlands

2 International Institute for the Dialogical Self, Milsbeek, The Netherlands

3 University of Utrecht, Utrecht, The Netherlands

4 Zomer \& Cornelissen, Eindhoven, The Netherlands 
Keywords Dialogical self theory · Multicultural identity · Multiracial identity ·

Transgender identity $\cdot$ Self-Categorization Theory

In the contemporary globalizing and boundary-crossing society many people are 'on the move' not only in a society which is changing as never before, but also within themselves. In their search to find a balance in complex and changing environments individuals are faced with the challenging question of how to organize their selves in adaptive ways. The purpose of this article is to discuss the viability of a democratic society metaphor for the organization of the self in an increasingly fluid and boundarycrossing world. In addressing this viability, we will focus on three groups of people who are very different from historical and societal points of view, but have in common that they need to find their way across the boundaries of established and dominating identity constructions: people with multicultural, multiracial and transgender backgrounds. Representatives of these groups are confronted with destabilizing situations that not only reflect power-laden differences in the society at large but also place them in fields of tension between opposing positions within their own selves. Our main argument will be that between power-laden ingroup versus outgroup dualisms fields of tension are constructed where new and hybrid identities are emerging, identities which are not fully recognized by established identity theories.

In the later parts of the article, we will use the discussion of multi-cultural, multi-racial, and transgender identities as a stepping stone for placing the democratic self in the broader context of democracy in the society at large. At this point we will draw on central elements of mainstream social identity theories to create a connection between social identity and recent proposals for a cosmopolitan democracy as required in a globalizing society. This article is an endeavor to study the potentials of the self from the perspective of a democratic society metaphor and its practical implications in a power-laden society.

We will start from two earlier metaphors, self as a totalitarian state and self as a bureaucratic organization, for the sake of comparison with the metaphor of the democratic self.

\section{Self as Society: Greenwald and Minsky}

A challenging proposal to conceive of the organization of the self in terms of a society metaphor was presented by Greenwald (1980) who demonstrated the striking analogy between the organization of knowledge in the self (or ego) and totalitarian informationcontrol strategies as exposed in George Orwell's 1984. In his depiction of the self, Greenwald discussed three cognitive biases found in attribution research: 'egocentricity' (perceiving one's self as more central to events than one actually is), 'beneffectance' (perception of responsibility for desired, but not undesired, outcomes), and 'cognitive conservatism' (the tendency to preserve existing knowledge structures together with a resistance to cognitive change). Greenwald argued that these biases have the advantage of realizing an effective organization of knowledge facilitating goal attainment. In his view, Orwell's characterizations of thought control at the level of a totalitarian society could represent a summary of cognitive biases in the intrapsychic organization of the individual self. 
However, purposeful as the totalitarian ego might be, a contradiction seems to exist between the self-centered nature of the individual's intrapsychic organization as depicted by Greenwald and the societal ideal of democracy, which is considered by many as one of the most cherished acquisitions of human civilization. How can selfcentered citizens contribute to a democratic society that requires them to decenter themselves as part of a larger community? Are self-centered individuals able to function in a democracy which invites them to be other-centered too? Before contrasting the totalitarian organization of the self with a democratically organized self, let's refer to another analogy between self and society.

In his ground-breaking work The Society of Mind (Minsky 1985), computer scientist Marvin Minsky made a bold attempt to explain how the mind works as a society of agentic parts. In the 1970 s, computer scientists were writing programs for robots that could see and move children's building blocks well enough to arrange them into simple towers and playhouses. In order to deal with the complicated management problems required by these tasks, Minsky (1985) devised a model in which the mind functions as a hierarchically organized network of interconnected parts, called 'agents' that together function as a 'society.' The different parts of the mind, like agents in a multilevel bureaucratic organization, work together to make it function as an organized whole. Agents at the lower levels, although they are parts of a functioning whole, are often not able to communicate with one another. Within their own programs, they are simply doing their job without knowing anything about the performance of the other agents. They can simply be turned 'on' and 'off' in the service of the higher agents in the organization.

The two metaphors presented have at least two features in common. They consider the self (Greenwald) and the mind (Minsky) as strongly hierarchically organized and, as central to the present article, the other (individual or group) as placed outside the self and not as an intrinsic part of it. The self as a totalitarian state is ego-centered and its organization does not allow others to express their unique voices, particularly if these voices represent a deviant or contrasting point of view. The mind as a bureaucratic organization analyzes the workings of basic human capacities and processes, like perception, memory, reasoning, and language, but it does not allow the agreeing and disagreeing voices of others as representing the society at large in the organization of the mind. Although the two metaphors have, without any doubt, merits in describing specific parts of human functioning they lack an explicit reference to an element that is essential to a democratically functioning self: recognizing the workings of other individuals and groups as intrinsic parts of an open and extended self.

\section{The Other as Part of the Extended Self}

The dualism between self and other and the lack of the other as an essential part of the self has been a topic of dispute in different theoretical domains. From a cultural point of view, cultural anthropologist Geertz (1979) noticed that the Western conception of the self is sharply differentiated from its environment. He described it as "a bounded, unique, more or less integrated motivational and cognitive universe, a dynamic center of awareness, emotion, judgment, and action organized into a distinctive whole and set contrastively both against other such wholes and against a social and natural 
background..." He considered this way of conceiving the self as "a rather peculiar idea within the context of the world's cultures" (p. 229).

From a social-constructionist perspective, Sampson (1985) characterized the Western ideal image of the self as 'centralized equilibrium structure': a distinctive entity with razor-sharp boundaries between self and non-self, with the exclusion of the other as an intrinsic part of the self and as persistently involved in a pursuit of having the environment under perfect control. Similarly, in contrast to what he called 'relational being,' Gergen (2009) criticized the 'bounded self' that emphasizes individual autonomy as a central element in Enlightenment views of the self. From a philosophical perspective, Dunne (1996) referred to the 'sovereign self' that is above all "its own ground" (p. 137) and traced this notion back to Descartes' rational knower whose ego has been isolated from its basis in language, culture, or community (see also Richardson and Woolfolk 2013).

A most compelling argument for the workings of society in the household of the self comes from sociologist Callero (2003) who listed and analyzed a series of psychological self-concepts in mainstream psychology (e.g., self-consistency, self-enhancement, self-monitoring, self-efficacy, self-regulation, self-presentation, self-verification, selfknowledge, self-control, self-handicapping). One of his main observations was a neglect of social power in the organization of the self:

...the self that is socially constructed is never a bounded quality of the individual or simple expression of psychological characteristics; it is a fundamentally social phenomenon, where concepts, images, and understandings are deeply determined by relations of power. When these principles are ignored or rejected, the self is often conceptualized as a vessel for storing all the particulars of a person" (Callero, 2003, p. 127).

There are not only critiques within psychology, sociology, and philosophy which question the self-other dualism, there are also theoretical reasons for the inclusion of the other and, more comprehensively, society as co-constituting and co-organizing the self.

\section{Inclusion of the Other in the Self in Classic Theories}

Main figures in American pragmatism were very well aware of the importance of the other as a co-organizing agency within the self. In his ground-braking chapter on the self, James (1890) argued that the self does not only include the Me (self as known) but also the Mine (e.g., my mother, my children, my friends). The gradual distinction between Me and Mine, later confirmed by Rosenberg's (1979) experiments with children, was reason for James to claim that the self can be understood as being 'extended' to the environment. This insight applied not only to individuals but also to groups, as exemplified by James's famous statement that the person "has as many different social selves as there are distinct groups of person's about whose opinions he cares" (p. 294).

Mead (1934), even more than James, emphasized the workings of society as coorganizing the self. Interested in the difference between 'play' and 'game,' he observed that, while play allows children to take the role of discrete others (e.g., playing the role of a police officer), a game requires them to take the role of everyone else involved in 
the same rule-guided activity. Game situations typically include different roles that are interconnected in prescribed ways and playing a game together requires the participants to take on all the roles as an organized arrangement. Along these lines he introduced his well-known concept of the 'generalized other,' which he conceived of as not a purely external other but as part of the self: "The group attitudes are brought within the individual's field of direct experience and are included as elements in the structure of constitution of the self..." (p. 158).

The inclusion of social groups in the self is also central in the thinking of the Russian literary scholar Bakhtin (1984), who proposed that all utterances are multivoiced and dialogical at the same time. In the act of speaking there are at least two voices: the voice of the individual and the voice of a social language (e.g., one's professional group, one's religious community, one's circle of friends). In this view, a word is always 'half foreign' as the collective voice of a social group expresses itself through the mouth of the individual speaker who personalizes this voice with his or her own intentions and individual expressions (e.g., I speak as a scientist but at the same time I give my own opinion). In the 'I' there is often an implicit 'we' which is personalized by the 'I.' The intense interconnectedness of self and other is further demonstrated by Bakhtin's (1984) notion of the other as 'another I,' suggesting that the other is an 'I' and at the same time another 'I.' This subject position of the other in the self resembles Aristotle's's (1954) characterization of a friend - at the highest level of friendshipas an 'alter ego': as ego the same as me and as alter different from me. The mutual belongingness and differentiation of self and other is also expressed by Buber (1970) who considered 'I' and 'you' as different but at the same time as parts of the same 'word pair.' Likewise, existential philosopher Heidegger (1996) made a strong case for the thesis that 'Sein' (being) is essentially 'Mitsein' (co-being).

In summary, talking about the relationship between self and other, including the connection between self and group and self and society, we are faced with an impressive contradiction: the Western ideal of the autonomous, highly individualized subject is juxtaposed with the views of a variety of classic theorists in philosophy and social sciences who claim that the individual can only function thanks to the other who plays a constitutive role in the self. In contrast to the ideal of the individualized person, many classic thinkers have persistently emphasized that the other, the group, and society co-constitute and coorganize the lives of individual people broadly and deeply.

The alternative metaphor, the self as a democratic society, is not only in agreement with the fundamental self-other connection and distinction as articulated in classical theories, but also functions as a desirable direction for the construction and development of a self in a contemporary globalizing and boundary-crossing society. Central to this view is the consideration that, like in a democratically organized society, fields of tension between different agreeing, disagreeing, arguing, and contesting positions or voices in the self exist, which, like parties or interest groups in a democracy, relate to each other in highly dynamic processes of positioning and counter-positioning (Hermans and Hermans-Konopka 2010) and of interchanging voices and countervoices (Valsiner 2005). [For the relationship between positions and contradicting positions, see Davies and Harré 2007; for the distinction between narratives and counter-narratives, see Bamberg and Andrews 2004; for the value of an open self see Oosterwegel and Oppenheimer 1993]. 


\section{The Analogy between Democracy in Society and Democracy in the Self}

At the end of the previous century, Amartya Sen (1999), Nobel Prize winner in economics, was invited by a leading Japanese newspaper to answer the question what he considered to be the most important thing that had happened in the twentieth century. In his reflections on this issue, he realized that many events of historical significance had taken place. European empires, like Britain and France, had come to an end. There were two world wars, which caused the untimely deaths of millions. The century witnessed the rise and fall of fascism and Nazism and, moreover, the rise and fall of communism (Soviet Union) or its radical transformation (China). The economic dominance of the West shifted to a new economic balance with countries in East and Southeast Asia becoming increasingly influential on the world stage. Sen realized that the past hundred years witnessed many important events. Nevertheless, he did not, ultimately, experience any doubt in choosing one development as most preeminent in that period: the rise of democracy.

In his further considerations, Sen observed that throughout the nineteenth century, theorists of democracy found it normal to consider the question whether a country was 'fit for democracy' or not. In the twentieth century, however, theorists started to recognize that the question itself was wrong: "A country does not have to be deemed fit for democracy; rather, it has to become fit through democracy" (p. 4, emphasis added). Sen considered this 'becoming' a momentous change, because democracy, conceptualized this way, had the potential to be extended to billions of people with very different histories and cultures and with disparate levels of affluence.

In our search for an analogy between a democratic society and the democratic organization of the self, Sen's dynamic view of democracy is particularly useful for the central thesis proposed in the present article. Democracy in the self is not a personality trait with individuals being rated below or above average. It is rather a pragmatic enterprise of both self and society that becomes true in its active realization. At its most basic level, democracy is not to be understood as a product or end-state but actually a desirable process of self-democratization and self-government (Charny 2006; Cruikshank 1999) as it requires a democratic willingness to be developed in the minds of the people.

What is a democratic self? In Sen's view, it would be an error to identify democracy with majority rule. Certainly, democratic practice may involve voting and respect for election results but it also requires the protection of liberties and freedoms, the guarantee of freedom of discussion and the uncensored distribution of information and comments. Sen considers political and civil rights, especially those that make space for open discussion, debate, criticism, and dissent, central to the process of generating informed and considered choices in which participants learn from each other. Advocating As part of a well-functioning democracy, he advocates tolerance of pluralism and the duty to protect minorities.

In an analogous way, a democratically functioning self gives space to the free expression and development of different, opposing, and contradicting I-positions which also enter into dialogical relationships, that is, open discussion, internal debate, and criticism from which they may learn in the service of their further development. This self is organized in such a way that other individuals and groups in the society at large are included as co-organizing parts and play contributing roles as positions in the minisociety of the self. 
I-positioning is a form of placing oneself vis-à-vis somebody or something else who is addressed as 'another I' in the metaphorical space of the extended self (Hermans and Hermans-Konopka 2010). We define the democratic self as a dynamic multiplicity and diversity of $I$-positions (e.g., I as a professional, I as a father, I as supporting a political party) in the landscape of the mind. This mind is intrinsically connected with the minds of other people (e.g., my colleagues, my children, my opponent) who function as other $I$-positions in the extended domain of the self. Between these $I$-positions fields of tensions are stretched where processes of positioning and counter-positioning occur in the form of sign-mediated interchange and cooperation. In agreement with Mead (1934), the person knows oneself via 'taking the role' of the other or, in our terms, via taking the position of the other as another I.

Fields of tension are reminiscent of self-discrepancies as introduced by Higgins (1987). Whereas Self-Discrepancy Theory is focused on negative experiences of conflicting perspectives, fields of tension not only lead to stress but can also have adaptive and creative potentials as we will see later in this article. A field of tension allows not only for movements between different $I$-positions but also for the emergence of new positions or coalitions of positions that were not there before the process of interchange started. In this constellation I-positions have the freedom to express themselves and communicate with other positions from their own specific experience and point of view.

In the organization of the self some positions or groups of positions are more dominant than others, which entails the risk that less dominant positions are silenced, suppressed or neglected. However, the self can be democratic only if these dominant positions contribute to decision making after consultation of and in dialogue with $I$ positions which are less dominant in the self. Dominant positions are part of a democratic organization if they respect and care for the development of less dominant and minority positions, including their wishes and purposes, as an expression of the value of equality in democratic relationships.

For a proper understanding of a democratic self, it is necessary to start from the assumption that the self is part of the society at large. An implication of this view is that relationships of social power that emanate from societal institutions, cultural values, and historical traditions, create both opportunities and obstacles for the development of the self. As part of the society, the self is challenged to respond, together or alone with other selves, to these power structures. If influential enough, this response has an impact on the further development of both society and the self. In this sense, a democratic self is 'work in progress' at the interface of self and society.

\section{Three Perspectives: Culture, Race, and Gender}

In this section we will apply the democratic metaphor to identity processes on the interface of self and a boundary-crossing society. Three perspectives are provided for further exploration: multicultural, multiracial, and transgender identities which have in common that they are located within fields of tensions. Each of these fields offer potentials of adaptation and function as spaces for the construction of new and hybrid identities. At the same time, they entail the risk of identity confusion and maladaptation. The concurrence of adaptation and maladaptation signifies the 'tension' aspect of the contact zones between multiple cultural, racial and gender identities. 


\section{Multicultural Identities}

The process of globalization and its counter-force localization engender contradictions and conflicts which are in some situations adaptive but in other ones maladaptive.

Adaptive Contradiction in a Cultural Field of Tension A clarifying example of an adaptive contradiction is given by Bhatia (2007), who investigated the identities of Indian Americans as one of the fastest growing immigrant communities in the United States. Participants in his research were educated as engineers, medical doctors, scientists, and university professors. Drawing on participant observation and in-depth interviews, the investigator found that these professionals function as respected members of American society, but feel at the same time that they are seen as racially different and not 'real Americans.' They emphasized that they were not only different from but also similar to members of the American majority, taking into account their individual merits as professionals and their successful integration into American society (e.g., 'I'm discriminated but I'm just as good as they are'). Although they and their children all had experiences with racism, they seemed to simultaneously accept and reject their differences from the majority, in this way being involved in a "doublevoiced discourse" (p. 158) between their individual voices and the majority's dominant voice. In contrast to universal models of acculturation in cross- cultural psychology (e.g., Berry 1997), Bhatia argues that a dialogical view does not insist that conflicting positions or voices need to be replaced by harmonious ones. Apparently, conflicting or contradicting voices may form a useful combination, helpful to coping with experiences of social discrimination (For similar results and conclusions in research in Ireland, see O'Sullivan-Lago and de Abreu 2010).

Maladaptive Contradiction in a Cultural Field of Tension In some cases, the field of tension between different cultural positions may result in identity confusion. An example is given by cultural anthropologist van Meijl (2012), who observed that the impact of migration is nowhere near as pervasive as in the Asia-Pacific region where young people, faced with limited prospects for economic growth and the effect of climate change, try their luck elsewhere. An increasing number of diasporic children and adolescents are growing up between two or more cultures, with migrants from Samoa and Tonga constituting the largest Polynesian groups in New Zealand. This requires of these youngsters that they develop multiple identifications with more than one place in and beyond New Zealand. Confusion occurs when their Samoan identity is challenged by island-born members of their extended family or church community. At the same time, their identity as a New Zealander is challenged by New Zealanders of European descent. They experience insecurity and lack of control, as they feel that social and cultural attitudes derived from their new environment conflict with the sociocultural norms established by their Pacific identity. As Van Meijl shows, their sense of self is divided between two cultural positions associated with inner voices that contradict each other to such a degree that it results in identity confusion.

As the studies above suggest, there is tension between cultural positions of multicultural identities associated with voices that give different or contradicting messages. This evokes a process of positioning (e.g., others tell me that I don't belong here) and counter-positioning (e.g., 'I as being proud of my own identity') in the self. In some 
cases this results in adaptive combinations (Bhatia's research), in other cases this results in identity confusion (Van Meijl's research).

Alternating between Cultural Identities In their influential article on the psychological impact of biculturalism, LaFromboise et al. (1993) put most emphasis on the 'alternation model' which posits that individuals are able to acquire competence within two cultures without losing their identity or feeling pressed to choose one culture over the other. The alternation model assumes that it is possible for individuals to know and understand two cultures at the same time and alter their behavior to fit a particular social context. As an example of the applicability of the alternation model, the authors refer to a study of biculturalism and adjustment of Ramallah-American adolescents by Kazaleh (1986). This study showed that these youngsters experienced identity conflict between their Palestinian background and the American mainstream culture. Yet, many of them, particularly those whose parents reacted with less anxiety to rapid changes, were able to acquire a range of mechanisms for dealing with this conflict and alternate between both cultural identities with a minimum of anxiety. From the perspective of the alternation model, it seems that the subjects of Bhatia's research were better equipped to develop a bicultural competence than the subjects of Van Meijl's project.

Third Space and Hybrid Identities An essential feature of the process of positioning is its spatial nature. Between different positions a field of tension is stretched in which new or hybrid positions have space to emerge which have the potential of broadening the array of adjustment strategies of individuals located at the interface of different cultures. Whereas the alternation model (LaFromboise et al. 1993) allows individuals to freely move from one to another cultural identity, it does not focus on the processes taking place in the field of tension between these identities. This field is a cornerstone in the theoretical framework of Bhabha (1994), a postcolonial political theorist interested in the role of culture and language in interactions and a keen observer of social alienation and political oppression. He proposes the notion of 'third space' as an ambiguous area that develops when two or more individuals or cultures interact. He claims that cultural statements and systems are constructed in a "contradictory and ambivalent space of enunciation," a concept that "challenges our sense of the historical identity of culture as a homogenizing, unifying force, authenticated by the originary Past, kept alive in the national tradition of the People" (p. 54). [For hybrid spaces created by diasporic migrations, see Kapchan and Strong (1999)].

In her interpretation of 'third space' in the context of linguistic communication, Wallace (2004) concludes that "the meaning of an utterance is neither precisely the meaning of the speaker (the I) nor the meaning of the listener/interpreter (the You). The spatial relation referred to by Bhabha might be considered a metaphor for the required distance placed between the meaning of the speaker and the meaning of the listener" (Wallace 2004, pp. 907-908, emphasis added). Rather, the third space is an area where meanings are co-constructed, where new hybrid meanings emerge, and where generative learning has a chance to take place: "Because language must travel through the Third Space, neither the speaker's nor the listener's state of understanding is privileged" (p. 908). [See also Morioka's 2015, discussion of the Japanese word 'ma' as an in-between space between 'I' and 'you,' which serves as a 'living pause' in the process of meaning construction (p. 81).] 
Hybrid Identities and Globalization Hybridity and globalization are closely allied. In her treatise on this topic, Smith (2008) notes that a hybrid identity is produced by a reflexive relationship between the global and the local. In the process of globalization, elements of different local cultures are combined and recombined to create new hybrid identities. In their interaction, the global influences the local and the local influences the global. At their intersection, hybrid identities rise from the encounter, conflict, and/or blending of social categories. Social power and hierarchy affect the process of globalization, resulting in an "uneven integration" of cultural elements and contributing to the emergence of diasporas and migration (Smith 2008, p. 3).

In their analysis of the repercussions of globalization for adolescence and emerging adulthood, Jensen et al. (2011) provide some telling instances of what happens at the interface of the global and the local. In China, a mass of factory girls in their late teens to mid-20s move from rural villages to large cities in an attempt to find work. While some of them attend English classes, others become escorts for wealthy businessmen with the intention to send their hard-earned money back home. In Chile, once one of the most conservative countries in Latin America, thousands of adolescents organize parties in which they violate the traditional sexual mores, promoted through the highly popular Fotologs and MSN Messenger. Or, a couple, an American woman and Greek man, marry in Paris, honeymoon in Africa, and then decide to reside in England. With these 'snapshots' Jensen and colleagues illustrate how hybrid identities emerge at the interface of the local and the global and become part of the identity development of adolescents and young adults worldwide in key areas such as marriage, sexuality, work, and moral values (for more examples of hybrid identities, see Hermans 2015).

Third Position in the Self The concept of 'third space' finds, on the level of the self, its theoretical equivalent in the notion of "third position" (Hermans and HermansKonopka 2010), in which two different, contradicting, or conflicting I-positions are combined or reconciled. An illustrative case is provided by Branco et al. (2008), who analyzed the story of a 25-year-old lesbian woman in Catholic Brazil. Located in the field of tension between her participation in a lesbian community and her position as daughter of a Catholic family, she began to see herself as a Christian woman who was motivated to help forsaken and lost people, including many gays and lesbians, living aimlessly in an intolerant society. Inspired by her Christian values, she started to assist people in the lesbian community to think about themselves and to change their life into a more positive direction. In this way, she reconciled her conflicting positions 'I as a Catholic' and 'I as a lesbian' by combining them in a third, more integrative, position 'I as a missionary.' For the development of self and identity in the field of tension between different cultural traditions and values, the construction of third positions is particularly valuable as they have the potential of transforming conflicts between $I$ positions into productive coalitions (Hermans and Hermans-Konopka 2010) (for the construction of third positions in the context of dialogical leadership, see Van Loon and Van den Berg 2016).

Multi-Cultural Identities and the Democratic Self What then is the relation between multi-cultural identities and a democratically organized self? As we have tried to demonstrate, bi-cultural or multi-cultural identities reflect a highly dynamic multiplicity of $I$-positions in a field of tension between different or even opposed cultural value 
systems. Other individuals or groups of individuals are not purely outside, but are, in the form of cultural positions, part of the extended domain of the self. This implies that others as representing power structures and institutions are part of this extended domain. Between internal positions and extended positions, fields of tensions are stretched that function as 'third spaces' in which interactions and dialogues between cultural positions and counter-positions in the self are taking place. In these fields $I$ positions are able or not able to construct adaptive hybrid identities or create integrative third positions. Democracy in the self implies that counter-positions get the opportunity to be heard and third spaces have a chance to emerge.

\section{Multiracial Identities}

In their review of studies on multiracial identities, Shih and Sanchez (2009) note that since the legalization of interracial marriages in 1967, marriages between people from different racial backgrounds have become more socially acceptable and that since then the number of multiracial children has grown exponentially. People of multiracial backgrounds have become one of the fastest growing minority groups in the United States. While in the late nineteenth century it was believed that group differences were heritable and that race was carried in the blood, the predominant view among social scientists today is that racial categories are socially constructed and are not fixed, immutable categories (see also Rockquemore et al. 2009). Racial distinction between different groups has changed over time in accordance with the cultural and political climate of the day.

Identification with Multiple Groups In their review of studies on racial identities, Shih and Sanchez (2009) note that multiracial people have developed more flexible understandings of race and race relations in comparison with monoracial individuals. For example, multiracial people have racial identities that often change according to social context. Moreover, multiracial individuals tend to question the fixed nature of the concept of race itself and tend to perceive race as a social construction more than individuals of a monoracial descent. Considering race as a social construction also has an impact on people's interpersonal and social relationships. Multiracial people tend to show greater comfort with interracial social interactions than other racial minorities and show less evidence of implicit racial bias for their multiracial group. Shih and Sanchez conclude that a fluid and flexible view of race is an important strength that is helpful to understanding race and race relations both in multi- and mono-racial communities (p. 7).

Binning et al. (1999) are among the researchers who argue that the distinction between multiracial individuals who primarily identify with one group and those who identify with multiple groups serves as a potentially meaningful division within the multiracial category. They asked high school students who belong to multiple racial/ ethnic groups to indicate the group with which they primarily identify. They classified the participants as identifying with a low-status group (i.e., Black or Latino), a highstatus group (i.e., Asian or White), or multiple groups (e.g., Black and White, etc.). They found that those who identified with multiple groups tended to report either equal or higher psychological well-being and social engagement in comparison with multiracial individuals who identified primarily with a low- or high-status group. 
Race and Third Space The concepts of 'hybridity' and 'third space' have attracted the attention of social-scientists concerned with racial differences. In their study of interracial families in Australia, Luke and Luke (1999) give ample attention to the historical background of racial opposites. They describe how the colonized, relocated, or dislocated object of modernism was defined as the 'other,' perceived as different from Anglo/European subjects who considered themselves as occupying the central position in the world. This 'other', living in de-centered places, was perceived as aberrant and as a deviation from the standard, and as the "constitutive negative principle on which the legitimacy of dominant interiority and territory as the positive principle depended" ( $p$. 226). White was seen as the "invisible center of normalization from which regimes of truth about difference(s) emanate" (p. 226). As part of a strategy of control and surveillance, groups of 'others' were located in particular places (e.g., isolated areas, ghetto's) separated from the spaces where 'truths' were defined and principles of normalcy produced and legitimated.

In this historical context, Luke and Luke use Bhabha's metaphor of 'third space' as opening up a conceptual domain that exceeds epistemological dualisms of insideroutsider or 'us' and 'them' classifications. They describe the third space as a site and moment of hybridity and ambivalence that allows to subvert and recreate existing identities and to liberate them from historically established social constructions of 'otherness' (being different from 'us', not like 'us').

Racial Identity and Moving through a Field of Tension The importance of a fluid and flexible view of race is further illustrated by the distinction between 'identity,' 'identification,' and 'categorization' as proposed by Rockquemore et al. (2009). They define racial identity as the individual's self-understanding, racial identification as how others understand and classify an individual, and racial category as what racial identities are available and chosen in a specific institutional or societal context. They demonstrate that in a multiracial identity these self-definitions do not necessarily coincide. One of their examples is Christy who as part of her college application process must check off a box designating her racial group membership. Despite her racial identity (she defines herself as multiracial) and physical appearance (she is identified by others as white), she checks off 'Black' (one of the available categories) on her admission form because she perceives it will give her an advantage in the admission process. As this example suggests, the distinction between identity, identification, and available categories places race at the interface of identity and society. Christy defines her own identity on the basis of her internal self; she knows that she is identified differently by others; and she makes an adaptive choice between the identity categories provided by the institution. The interface between self and society functions as a field of tension between different positions among which the individual can move, shifting from one to the other position and constructing a pattern of positions depending on self-definitions, other-definitions, and institutional opportunities and restrictions.

Institutions and Identity Denial However, moving between racial positions in fluid and flexible ways is far from self-evident. A most compelling example of institutional restrictions are government-created definitions in the form of census categories. Prior to the 2000 Census, multiracial individuals were required to choose only one race category on the U.S. Census. In the controversy around this issue, multiracial groups 
argued that the limitation of selecting only one identity category forced multiracial individuals to deny other parts of themselves and, therefore, the Census did not accurately reflect the true racial makeup of the country. The controversy was finally resolved in 1997, when it was recommended that multiracial individuals could check off more than one racial category, although the category 'multiracial' was not included in the census forms (Shih and Sanchez 2009).

The consequences of identity denial were empirically assessed by Townsend et al. (2009). In their research, some participants were given the option of selecting multiple racial backgrounds, whereas others were forced to choose one only. They found support for the claim that forcing biracial or multiracial individuals to choose a single, monoracial identity rather than permitting multiple selections leads to subsequent lower self-esteem and motivation. [See also Jones's 2015, research demonstrating that the racialized norms of a 'predominantly white institution' affect multiracial identities and limit their diversity.]

Multi-Racial Identities and the Democratic Self As the literature in this section suggests, there is a field of tension between different racial positions as parts of multiracial identities. This field allows individuals to move from one position to another dependent on the social and societal context. The field functions as a fertile soil for processes of positioning and counter-positioning in a dialogical self (e.g., others see me as..., but I disagree with the category in which they want to place me') and for the emergence of third spaces (see also König 2009). However, power-laden institutional restrictions may impede flexible movements in the self-space and limit the freedom to navigate between different racial identity positions, with the consequence of identity denial and the silencing of significant voices in the self. As a result the multiplicity and diversity of the dialogical self are reduced. When counter-positions, alone or in combination with other positions, are strong enough to provide a successful counter-weight to powerful others-in-the-self, the democratic self has the opportunity to construct an in-between space in which positions are free enough to express their voice and to contribute to their own and each other's development.

\section{Transgender Identities}

Transgender is considered an umbrella term, typically used to identify individuals with a gender identity or expression that differs from the culturally defined gender associated with one's assigned sex at birth (i.e., male or female) (Davidson 2007; Hughto et al. 2015; Valentine 2007). Transgender does not only include people whose gender identity is the opposite of their assigned sex (trans men and trans women), it also refers to people who are not exclusively masculine or feminine, usually called genderqueer (e.g. bigender, pangender, genderfluid, or agender) (Nestle et al. 2002).

As Grossman et al. (2005) observe, transgender youth face many obstacles in their transition from birth sex to transgender identity because they transgress society's established binary categorization of two types of bodies, male or female, and two types of gender expression, masculine and feminine, which prevents them from moving to inbetween positions which are more congruent with their own gender experience. As a result, many transgender youth live in fear of being ridiculed and rejected by family, 
especially their parents. Grossman and colleagues note that $59 \%$ of their participants faced initial negative reactions from their parents, although some youth reported that both their mothers' and fathers' responses improved over time. The more gender nonconforming youngsters were, the more physical or verbal abuse they received. The authors refer to earlier findings suggesting that, when children are abused, they learn to protect themselves by denial, withdrawal, turning off their feelings, acting out, or selfblame with long-term consequences, such as low self-esteem, problems with knowing or showing one 's feelings, and experiencing poor mental and emotional health.

Although gender and sex have to be distinguished, they are often studied in combination. According to Bilodeau and Renn's (2005) review of literature, scholars increasingly recognize the experience and diversity of sexual orientation beyond 'heterosexual,' 'gay,' and 'lesbian' identities. They found that the identity development of bisexuals is more complex and unpredictable than the development of lesbians and gay men. Some individuals may come to bisexual identity after labeling themselves as lesbian or gay. Others may experience bisexual feelings from childhood onward. Still others may not become aware of bisexual feelings until after experiencing heterosexual relationships. The researchers suggest that the binary male or female category system leads to negation of the existence of more fluid gender identities increasingly expressed by transgender youth in their exploration of identity positions located between the dominating binaries.

Fluidity versus Gender Binaries Inspired by the postmodern gender theorist Butler (1990), many researchers consider gender as performative and fluid. In linguistic circles, performativity is a term used to refer to the capacity of speech not simply to communicate but rather to act or to construct and perform an identity. A common example is the act of saying "I pronounce you man and wife" by a licensed minister in a marry ceremony or "I do" by the marrying individuals. In Butler's view, gender is also 'fluid' in the sense that bodies are not circumscribed by a hegemonic duality of sex but fluctuate among multiple gender identities. By transgressing the limiting boundaries of established identity positions, theorists in this tradition aim to undermine the power of essentialist discourses on gender and body. One of them, Doan (2010), proposes that gender is not a dichotomy but a "splendid array of diverse experiences and performances" (p. 638) and she resonates with Bondi's (2004, p. 12) argument that "the binary construct of gender ... [is] a superfluous and unnecessary distraction from the reality of the human condition" (see also Bornstein's 1994, discussion of gender fluidity).

Gender theorists emphasize the highly dynamic and border transcending quality of gender positions and claim the existence of a field of tension beyond institutionalized gender dichotomies in which they aspire to freely move in a unconstrained process of positioning, counter-positioning and repositioning. They reject boxes and boundaries that maintain fundamental inequalities of gender and sex (Doan 2010) and claim a dynamic multiplicity of gender-positions, moving freely in fields of tension between the imprisoning binaries. This view resonates with theorists who push for new understandings of the "spatializing of gender" and the "creation of gender through sociospatial relations" (Browne et al. 2010. p. 573).

Transgender and Health Given the fact that people with transgender identities have to cope with institutionalized power structures and prejudices, the question can be 
raised to what extent the in-between space between established binaries is a healthy place to be. Hughto et al. (2015) demonstrate in their review that the transgender stigma limits opportunities and access to resources in a number of critical domains, such as employment and healthcare, with the consequence of persistently affecting the physical and mental health of transgender people. In their social ecological model, transgender stigma is studied at multiple levels (i.e., individual, interpersonal, structural). At the individual level are, for example, concealment, avoidance, or internalization of stigma. At the interpersonal level, they refer, among others, to workplace limitations, healthcare discrimination, and family rejection, and at the structural level, they mention gender conformity to natal sex norms, stigmatizing policies, and lack of provider training and education.

From a somewhat different angle, Vaughan and Rodriguez (2014) embarked on understanding lesbian, gay, bisexual, and transgender (LGBT) individuals and communities from the perspective of positive psychology. Termed 'LGBT strengths,' this perspective aims to complement existing perspectives in LGBT psychology focused on distress and pathology with a more balanced and representative understanding of LGBT lives. Vaughan and colleague present empirical evidence showing that bisexual individuals have more social awareness and are better able to modify their behavior to address unique situations and problems in comparison with both heterosexuals and LG individuals. Similar themes are found among transmen and women who reported that their gender-specific experiences gave them insights into what it means to be both male and female on social and emotional levels. The authors argue that LGBT individuals who are members of multiple minority groups may be well-equipped to use and develop social intelligence to select and evaluate social information in settings where one minority group predominates. This stimulates them to develop the cognitive flexibility that enables them modify their reactions to maximize their own psychological and social wellbeing (see Konik and Crawford 2004, for similar findings). Vaughan and Rodriguez (2014) argue that scholars should recognize and reframe difference as a potential source of strength and growth, while at the same time studying the negative effects of marginalization, exclusion, and discrimination (p. 331-302).

Transgender and Institution Given the significant role of social power in the lives of LGBT individuals and other minority groups, it is worth to also take institutional opportunities and constraints into account. Traditionally, medical and psychiatric literature has confirmed a binary construction of gender identity. A section on Gender Identity Disorder (GID) appeared for the first time in the 1980 Diagnostic and Statistical Manual of Mental Disorders (DSM-III) and was continued in the DSM-IV. As instigated by many oppositions and controversies surrounding gender identity, the American Psychiatric Association (APA) decided to change the label 'gender identity disorder' into 'gender dysphoria' in the DSM-5 (American Psychiatric Association 2013a). In a recent APA document, it was written: "It is important to note that gender nonconformity is not in itself a mental disorder. The critical element of gender dysphoria is the presence of clinically significant distress associated with the condition" (American Psychiatric Association 2013b, n.p.). This change like other changes in psychiatric diagnostic labels and criteria are in support of the consideration that such categorizations are social constructions which are historically situated and institutionalized. 
Transgender Identities and the Democratic Self As the literature discussed in this section suggests, there is a field of tension between different gender positions as parts of multi-gender identities. This field allows individuals to move from one position to another dependent on social and societal situations. In this in-between field individuals may locate themselves as being in a masculine and feminine position simultaneously or successively (bigender); or experience themselves as a dynamic mix of male and female, feeling more male some days or in some situations, and more female other days or in other situations (gender fluid); or cover the whole field in their desire to identify themselves with all genders (pangender); or may define themselves as genderless or gender neutral (agender); or move away from the gender domain and identify themselves with the more general position 'I as a person' or 'I as a human being.' The field of tension where gender identities try to find their place functions as a fertile soil for processes of positioning and counter-positioning in a dialogical self ('Others tell me that I'm....., but I feel...') and for the formation of hybrid forms of identity. The tension between identities is further expressed by the fact that for many youngsters feeling placed in the space between gender binaries has maladaptive consequences (e.g., rejection and loss of self-esteem).

Culture, Race, and Gender: Summary Taken together, theory and research on multicultural, multi-racial, and transgender identities shows an increasing awareness of the importance of the existence of fields of tension between traditional or established cultural, racial, or gender positions in the self. People with multiple identities are involved in a struggle to transgress the closed boundaries of power-laden binaries (e.g., Indian or American, black or white, man or woman) and are faced with obstacles to move freely among a larger variety of in-between positions which better fit their selfexperience. A significant implication of this view is that the realization of a preferred cultural, racial, or transgender identity requires a process in which significant others, as powerful positions in the extended self, receive counter-positions (e.g., 'I as different' or 'I as a valuable person') that are strong enough to create a healthy and identityconfirming balance in one's self-organization. However, power-laden institutional restrictions may impede the process of positioning and counter-positioning and limit the freedom to navigate between different identity positions, with the risk of identity denial and the silencing of significant voices in the self. As the literature discussed in the preceding sections suggest, positioning and counter-positioning processes are not restricted to a self in isolation. They occur on the interface between a changing self and a changing society. Although this is a long-term process, the claim for freedom of space and voice in the area of identity construction is not without success (see the examples above such as allowing the choice of more than one racial category in the US census and changing 'gender identity disorder' into 'transgender dysphoria' in the DSM-5 classification system of the American Psychiatric Association).

In our review of studies in this section, we included, in each of the three areas (culture, race, gender), evidence suggesting that fields of tension offer both new opportunities (e.g., flexibility of adaptation, improved health, enhanced creativity) and risks (e.g., identity confusion, health problems, loss of self-esteem). The concurrence of adaptation and maladaptation reveals both the psychological opportunities and the dangers of these spaces of tension.

In our contemporary society, the dialogical self is faced with the difficult task of creating a well-balanced organization of a highly dynamic multiplicity and diversity of 
I-positions and we-positions in a society that provides the individual not only with enriching opportunities but also with established and institutionalized obstacles. In terms of a democratic self, these I-positions deserve, in the service of their further development, both freedom and care.

\section{The Democratic Self in a Broader Social and Global Context}

In the preceding section we have dealt with cultural, racial, and gender identities in order to demonstrate the relevance and fertility of fields of tension for the understanding and development of a democratically organized self. It is our purpose to use the preceding discussion of these identities as a stepping stone for placing the democratic self in the broader context of democracy in the society at large. Indeed, we can only understand the workings of the self as a democratic micro-society of I-positions, if we can place it in the broader context of democracy and its potentials in a globalizing world. In order to achieve this task, we will discuss psychological identity theories, particularly Self-Categorization Theory, in the context of recent proposals for a cosmopolitan democracy. In order to do this, we shortly refer to research on the extension of the self in social psychology and then expand on this literature by addressing the relationship between identity and cosmopolitan democracy.

\section{The Extension of the Self in Social Psychology}

Social psychologist have given significant contributions to the empirical investigation of the extension of the self. Some examples are Aron et al.' (2005) inclusion-of-otherin-the-self model, Ogilvie and Ashmore's (1991) research on self-with-other, Andersen and Chen's (2002) model of the relational self, Baldwin's (2002) concept of 'relational schema,' Crocker and Luhtanen's (1990) proposal of collective self-esteem, and Sedikides and Brewer' (2001) distinction between individual self, relational self, and collective self.

Social Identity Theory and Self-Categorization Theory Most significant for our proposal are Social Identity Theory (SIT) (Tajfel and Turner 1979) and SelfCategorization Theory (SCT) (Turner et al. 1987). SIT posits that social groups shape the self of their members through shared norms, beliefs, and values. The collective identity of the members is formed by the contribution of group membership to the self and members derive self-esteem and distinctiveness by drawing favorable comparisons between the ingroup and outgroup on valued dimensions. Self-Categorization Theory, an offspring of SIT, provides a cognitive explanation for how individuals identify and act as members of a group. Both theories have spawned an impressive amount of empirical research in a wide range of research areas (for review and discussion, see Hogg and Terry 2000; Hornsey 2008; Huddy 2001; Simon and Klandermans 2001; Sindic and Condor 2014).

For present purposes, we focus on one aspect of Social Identity Theory and SelfCategorization Theory, the role of power. Elaboration of this aspect contributes to the articulation of the specific contribution of the concept of the democratic self. 
The Role of Social Power Although they acknowledge the potential merit of Social Identity Theory to political psychology, Sindic and Condor (2014) notice that the theory's focus on identity management strategies may have had the implication of downplaying the political aspects of intergroup relations, since the primary goal of these strategies has been understood as being about status rather than power. They observe that: "In so far as they have addressed issues of power, Social Identity theorists have tended to focus on the ways in which power may impact upon the quest for positive social identity, rather than focusing upon political power as a key problem in its own right" (n.p). The importance of social power in the society at large is emphasized by Simon and Klandermans (2001) who, in their treatise on 'politicized collective identity,' proposed a three pillar model, in which collective identity (pillar 1) is accompanied by the struggle between groups for power (pillar 2), and the wider society in which these struggles are taking place (pillar 3).

Social identity and self-categorization theorists have not neglected power in a broader sense of the term. Hogg and Terry (2000), for example, deal extensively with issues of social power, although they observe that traditionally social identity theorists prefer to talk of 'influence.' One of the founders himself, Turner's (2005), has explicitly focused on social power. In his view, the most general meaning of power found in both the literature and everyday thinking is "that it is the capacity to cause effects, to have an impact on or change things, to do "work', either in the physical or social world" (p. 6). He added a sub-category of power which he defined "as the capacity in some way to affect people or society, to cause them to do things that they would not otherwise have done" (p. 6). It is precisely this kind of power that is exercised when people find themselves located in situations where they are exposed to cultural domination, racial discrimination, and gender binaries. In terms of Simon and Klandermans, this kind of power does not only take place between isolated ingroups and outgroups, but is rooted in the society at large, including its established institutions with their roots in cultural and historical precursors.

\section{Levels of Inclusiveness and Cosmopolitan Democracy}

One cornerstone of Self-Categorization Theory is of utmost importance for understanding the identity implications of a globalizing and border-crossing world and for mitigating the power struggles between ingroups and outgroups: the distinction of different levels of inclusiveness (Turner et al. 1987). Rather than perceiving intergroup dynamics as opposite ends of a bipolar spectrum, Turner and colleagues characterize identity as operating at different levels of inclusiveness. They nominate three levels of self-categorization: the subordinate level of personal self-categorizations based on interpersonal comparisons (personal identity), the intermediate level of the self as a member of an ingroup, distinctively compared with outgroups (social identity), and the superordinate category of the self as human being (or human identity).

An empirical implication of this level distinction was provided by Wohl and Branscombe (2005) who performed research in groups of Jewish North Americans and Native Canadians. They tested whether increasing category inclusiveness, from the intergroup level to the more inclusive human level, would lead to greater forgiveness of historical perpetrator groups. They found that human-level categorization resulted in 
more positive responses toward Germans and White Canadians by decreasing the uniqueness of their past harmful actions toward the ingroup. The authors concluded that "The results of our four experiments clearly indicate that negative group-based feelings toward the perpetrator category can be reduced with more inclusive levels of categorization" (p. 301). Such findings suggest that taking the position of "I as human being' results in more forgiveness than less inclusive $I$-positions of ' $I$ as a Jew' or 'I as native-Canadian.'

From a dialogical perspective, the hypothesis seems plausible that one's initial positioning to other groups can be followed by climbing to a higher level of inclusiveness as a counter-positioning answer to one's reaction at a lower level (and vice versa). Allowing a space for moving between the ingroup position and the human position would serve as a field of tension where the initial (emotional) ingroup response could be mitigated and modified by taking a responding human position. Therefore, we consider the level-distinction in Self-Categorization Theory as a useful framework for a dialogical conception of the self in the context of a deliberative democratic framework.

Deliberative Democracy As proposed earlier in this article, a democratically organized self functions as a micro-society giving space to the free expression and development of different, opposing, and contradicting I-positions with mutual dialogical relationships from which they may learn in the service of their further development. At the level of society at large, the proposal finds its parallel in what is generally called 'deliberative democracy' (see also Fishkin 1991). In his treatise of models of democracy, Held (2006), maintains that the key focus of deliberative democracy is not in the exchange of fixed opinions or preferences but in the process of their formation (p. 233), that is, in the deliberation itself. Held proposes that this form of democracy bids farewell to any fixed political preferences and replaces them with a learning process that leads them to sound and reasonable political judgments (see also Sen 1999). At this point Held emphasizes the moral dimension of deliberative democracy: “...individual points of view need to be tested in and through social encounters which take account of the point of view of others - the moral point of view" (p. 233). This principle requires adopting a "multi-perspectival" (p. 233) way of forming, defending, and refining our political preferences. In its focus on learning, multi-perspectivity and incorporating the perspective of the other, deliberative democracy not only parallels a dialogical view of the self as a dynamic multiplicity of $I$-positions extended to the positions of the other but also provides a conceptual link between the mini-society of the self and the larger framework of a deliberative democracy.

Our emphasis on the process of positioning and counter-positioning as a learning device for developing a democratic self, is directly addresses by political theorists Offe and Preuss (1991) who in their aim to upgrade the quality of citizenship in a democratic society put a premium on reflected preferences and dialogical relationships within the self:

...preferences that are the outcome of a conscious confrontation of one's own point of view with an opposing point of view, or of the multiplicity of viewpoints that the citizen, upon reflection, is likely to discover within his or her own self. Such reflectiveness may be facilitated by arrangements that overcome the 
monological seclusion of the act of voting in the voting booth by complementing this necessary mode of participation with more dialogical forms of making one's voice heard (Offe and Preuss 1991, p. 170, emphasis added).

We consider the construction of fields of tensions in the self where opposing $I$ positions find space for reflection, dialogue, and learning as essential to a democratically organized self and as a prolific basis of a democratic society at large (for the limits of deliberative democracy, see Blattberg 2003; see Held 2006, pp. 234-237; see also further in this section).

Cosmopolitan Democracy and Levels of Inclusiveness We want to push our argument for a democratic self one step further by creating a conceptual link between deliberative forms of democracy and the highest level of inclusiveness in SelfCategorization Theory: 'I as a human being.' This link is provided by Held's (2006) view of 'cosmopolitan democracy.' As he observes, the modern theory of the sovereign state which governs itself and determines its own future is challenged by the increasing pattern of global interconnections (e.g., by immigration, tourism, media, finances, economy and ecology, see also Appadurai's 1990, global landscapes). Democracy is not only a national but also a transnational affair as it is no longer restricted to a limited geographical area but extends to a wider international community. Held notes that this development not only requires new democratic institutions but also broad avenues of civic participation and deliberation in decision making at regional and global levels (e.g., transnational deliberative assemblies, reform of leading UN governing institutions, the desirability of a global parliament). He advocates "the recovery of an intensive, participatory and deliberative democracy at local levels as a complement to the deliberative assemblies of the wider global order" (pp. 307-309). In such an order of democratic associations, cities, nations, regions, and global networks, "the principle of autonomy would be entrenched in diverse sites of power and across diverse spatial domains" (p. 309).

The emergence of a cosmopolitan democracy, functioning at different levels of democratic organization and requiring deliberative skills in a multiplicity of social and societal domains, would require the capacity and flexibility to move hence and forth between different $I$-positions in a democratically organized self. Part of this requirement is the flexibility to move across different levels of inclusiveness (personal, social, and human) with the human level as a psychological concept that corresponds with globalization as a sociological trend and with cosmopolitan democracy as a political telos. From a democratic point of view, it is plausible to expect that the incorporation of the human level in the position hierarchy of the self is facilitating the emergence of 'global consciousness' defined by Liu and Macdonald (2016) as "a knowledge of both the interconnectedness and difference of humankind, and a will to take moral actions in a reflexive manner on its behalf" (p. 1). [For criticism of cosmopolitan democracy, see Archibugi 2004].

\section{Social Power in an Agonistic Democracy}

There is, however, a serious lacuna in models of deliberative democracy: the role of social power. This is of central concern in the work of political scientist Mouffe (2000). 
Her main thesis is that democratic theory needs to acknowledge the ineradicability of antagonism in a democratic society and the impossibility of achieving a fully inclusive rational consensus in deliberative democracy. She argues that a model of democracy in terms of 'agonistic pluralism' is most appropriate in democratic politics today, faced as society is with the difficult question of how to create democratic forms of identifications in a context of social power.

In a historical account of democratic models, Mouffe explains that advocates of deliberative democracy proposed forms of normative rationality, as a corrective response to impoverishing utilitarian versions of democracy, with their purely instrumental means-ends procedures. Main representatives of deliberative democracy, John Rawls and Jürgen Habermas, have proposed versions of moral democracy that go beyond instrumental rationality. A significant convergence of these thinkers is their common insistence on the legitimacy of public reasoning and a belief in forms of rationality which are not merely instrumental but have a normative basis. Habermas finds this basis in 'communicative rationality' and Rawls in the 'reasonable.'

Although Mouffe resonates with the deliberative democrats' aim to go beyond models of pure instrumentality and to include a normative dimension, she holds that theorists like Habermas and Rawls fail in providing an adequate basis for democracy, because they leave aside the crucial role played by passions and social power. They treat individuals as "abstracted from social and power relations, language, culture and the whole set of practices that make the individuality possible" (p. 10).

In an attempt to remedy the deficiencies of the rational approaches, Mouffe proposes a model of 'agonistic pluralism' which places power and antagonism at its very center. In this model, power is not to be understood as a process taking place between two preconstituted identities, but rather as constituting the identities themselves. Held (2006) also points to the inevitable influence of social power, even in situations where participants pretend to be 'impartial.' Dominant individuals or groups have their own established ways of reasoning and their high status position add to the weight of their argument apart from the content of their view. Even when participants pretend to speak as free and equal individuals, the result has often been a conflictual situation of argumentation, oriented to winning or convincing the others of one's own point of view.

Taking into account the pervasive influence of emotions and social power, Hermans (2017) has proposed a distinction between consonant and dissonant forms of generative dialogue (Hermans 2017). While consonant dialogue is based on commonality among participants with an emphasis on agreement, dissonant dialogue gives room for different, contradictory, and deviant voices that profit from disagreement, opposition, conflict and clashes. In dissonant dialogue, identity differences, contradictions, and oppositions between the participants are actively and creatively employed as starting points for the exploration of common points of view and decision making. A most realistic picture seems to be that in a generative dialogue, dissonance and consonance alternate with consonance producing commonality and efficiency and dissonance stimulating change and innovation (Hermans 2017). This alternation creates a dialogical space in which people can meet not only in their commonalities but also in their differences.

The place of social power in a model of democracy is crucial to our proposal of a democratically organized self. As we have argued in the first part of this article, social power and its workings in the intimate domains of the self, are central in the 
organization of the self in fields of tension between cultural, racial, and transgender $I$ positions (see Callero, 2003, who considers the self as deeply determined by relations of power).

\section{Model of a Democratic Self}

The preceding considerations lead to a model (Fig. 1) of the democratic organization of the self with three dimensions: levels of inclusiveness (personal, social, global); self and other, with the other as extension of the self; and dialogue and power, stretched between levels (vertical ellipses) and between self and other (horizontal ellipses). Within these fields of tension, I-positions are located in the form of singular and plural pronouns. As subject positions they are addressable in dialogical relationship which carry the potential of stimulating their free expression and further development. These positions, however, are, at the same time, part of relationships of social power that may facilitate, limit, or block the free expression of the I-positions, their exchange with other positions, and their further development. The theoretical concept of I-position is not to be understood as an isolated entity but as a bridge to other persons or groups who are conceived of as 'another I' or 'another we' in the extended domain of the self. For a proper understanding of the concept of I-position it should be added that in its extended nature it is broader than the colloquial words 'I' and 'we.' A person or group which is subjectively defined as 'not me' or 'not like us' can certainly play as 'my opponent,' 'our enemy' or 'discriminating people' an organizing and even power-laden role in the extended self.

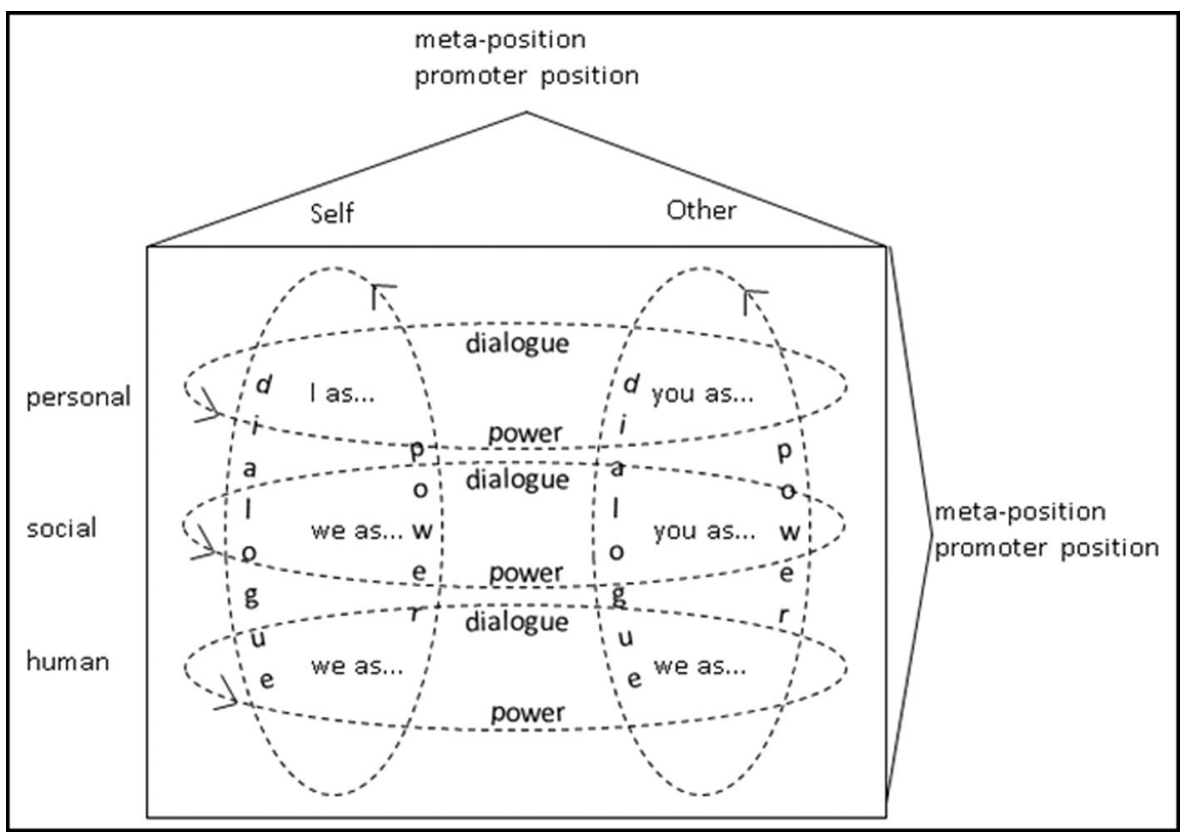

Fig. 1 Fields of tension in the self 
For theoretical reasons the model includes the other person or group as subject position ('you'), that is, as dialogically addressable (Bakhtin 1984; Buber 1970), with the connotation that subjectively the other can be experienced as a third-person category ('him,' 'her,' them,'), and perceived, particularly in situations of threat, anxiety, and xenophobia, as an object, even as an abject (Kinnvall 2004; see also Buber's 1970, distinction between I-you and I-it).

The central part of this article was focused within personal and social fields of tension (horizontal ellipses) — between self and other in multi-cultural, multi-racial, and transgender positions. That is, powerful others (e.g., parents or teachers) or groups of others (e.g., schools, political parties) play as 'others-in-the-self' an organizing role, facilitating or limiting the free expression and development of cultural, racial, and gender positions in the self. In these fields new or hybrid positions may emerge (e.g., Branco et al.' 2008, case of the missionary as a third position on the personal level and the examples of third space on the social level).

In the third and final part of this article, we placed cultural, racial, and gender positions in the broader context of a boundary-crossing, globalizing society. This enabled us to propose a theoretical link between 'we as human' at a high level of inclusiveness and the concept of cosmopolitan democracy. We consider the accessibility of this level in the self as a prerequisite to the development of global consciousness (Liu and Macdonald 2016).

The three levels of inclusiveness allow the distinction of three kinds of responsibility: personal, social, and global. Responsibility is understood in its two components 'response' and 'ability': the ability to give dialogical answers to others and oneself from one's personal $I$-positions (personal responsibility); the ability to give dialogical answers to others and oneself from the we-positions of the group or social category to which one belongs (social responsibility), and being able to provide dialogical responses to others and oneself from the more general position of human being (global responsibility). Stimulating responsibility at the global level has far reaching implications for long-term goals not only on the individual level but also on the level of collectives (e.g., families, clans, tribes, political groups, commercial organizations), given the irreversible trend of transcending cultural, social, and political boundaries and given a situation of increasing global interdependence. A democratic self with global responsibility finds a warm and prominent advocate in Nelson Mandela who, at the occasion of receiving the Nobel Peace Prize for his long struggle against apartheid in 1993, said: "We need a globalization of responsibility as well. Above all, that is the challenge of the next century" (Mandela 2000, p. 35).

Flexibility and Motivation The question then is raised whether one is able to move from the lower levels to this higher level inclusiveness and responsibility, a question that brings us to the field of tension between the (vertical) levels of inclusiveness. At this point, we face an obstacle emanating from the specific nature of the human level. As Rosenmann et al. (2016) have argued, more inclusive and abstract groups and communities are less motivationally satisfying, in terms of self-esteem, distinctiveness, and belonging, than more immediate, particularistic identifications. They refer to optimal distinctiveness theory (Brewer 1991) which suggests that very large social categories are unlikely to provide a satisfactory balance between the opposing motivations of belonging to a category or group and being distinctive at the same time, 
because these categories are too inclusive to allow differentiation from other categories or groups.

An answer to this balance problem can be given by focusing on the (vertical) field of tension between the social and human level of inclusiveness. The imbalance would be redressed by assimilation to groups that have a task or purpose at the human level but are organized in a group or community small enough to allow distinctiveness from other groups. An example of such a group is Amnesty International, a global nongovernmental organization devoted to the protection of human rights with over 7 million members and supporters around the world. In countries where the organization is highly prominent, members are organized as 'sections' which co-ordinate basic international activities. The sections have a significant number of members, some of them working in smaller groups, and they have a professional staff. The organization has also 'international networks,' which promote specific themes and have a specific identity. Such a 'hybrid' organization, located in the field of tension between the global and local level, allows its members to engage in a global telos while having the opportunity of fostering a distinctive identity at the same time. Such a constellation allows individuals to derive distinctive self-esteem from group membership and to experience empathy and moral dedication at the level of global consciousness.

Meta-Position Given its multi-level identifications and multiplicity of positions at the interface between self and other, the democratic self is faced with a considerable complexity. When the self would be distributed into an almost unlimited amount of positions and when each of these positions would follow their own specific developmental trajectories, then the self-system would be at risk of becoming disorganized or fragmented. Therefore, special positions are needed for introducing the necessary coherence and organization into the self-system. Two kinds of positions are proposed to serve this function: meta-positions and promoter positions (Hermans 2017; Hermans and Hermans-Konopka 2010).

A meta-position, like meta-cognition (Flavell 1979; Hussain 2015), provides an overview of more specific I-positions, including their patterns and inter-relationships. In its most typical form, a meta-position offers a distant view on a greater variety of specific positions, their mutual linkages and their associated voices and narratives (e.g., 'when reflecting about myself, I noticed that when sharing my experiences with my colleague, I became aware of things that I simply did not see when I discussed them with my partner'). Meta-positions can also be taken by groups or organizations when they address problems on a group or global level (e.g., immigration, sustainability, ethnic prejudices, animal rights).

For our purposes, the organization of specific $I$-positions under the helicopter view of the meta-position is particularly relevant. Like 'I' versus 'you' antagonism on the personal level of inclusiveness, strong ingroup favoritism may result in prejudice, rejection, and repressive power regarding the outgroup on the social level. Such separations and antagonisms may be mitigated or even transcended by the capacity and willingness to move from the personal or social level of inclusiveness to the human level and back to the lower levels again. These movements would serve as a facilitating condition for dialogical relationships between positions located at different levels of inclusiveness. We predict that a process of positioning and counter-positioning in fields of tension between different levels of inclusiveness (vertical movements) would 
facilitate the prevalence of dialogical over power relationships between self and other (horizontal movements), a process that would contribute to a self that, in terms of Sen (1999) would become fit to democracy in a globalizing world. A meta-position which has access to a broad bandwidth of specific positions in the self enables the individual or group to consider both the nature of the relationship between self and other and between different levels of inclusiveness. Along these lines, we expect that such a meta-position is equipped to open closed boundaries between different cultural, racial and gender positions.

Promoter Position Like meta-positions, promoter positions have an important task in the organization of the self-system. Analogous to inspiring leaders in society, they imply a considerable openness towards the future and have the capacity of organizing and producing a diverse range of more specialized positions that are relevant to the further development of the self, in this way operating as innovators of the self. They have a 'compass function' and provide a sense of direction to the self-system as a whole. Promoters work not only in society at large but also in the mini-society of the self. As promoting positions they can be adopted and further developed as parts in the extended domain of the self. For some it may be a well-known person who reaches the status of a hero or heroine, like a Mandela, a Ghandi, a Malala Yousafzay, a pop artist, an admired film actor, or an imaginary figure from a book. For others a person living in their immediate environment may function as a promoter: a parent, a grand-parent, a dedicated friend or a psychotherapist. Such people may enter the metaphorical space of the extended domain of the self and become established as valuable sources of energy, inspiration, and motivation. Promoter positions can also be at work in the internal domain of the self where they play an organizing and direction giving role (e.g., I as taking care of my family, I as a dedicated professional, I as an inspiring teacher). Often such internal promoters are generated as a response to influential promoters in the extended domain of the self and serve as significant role models (Hermans and Hermans-Konopka 2010).

As recent social and political clashes in a wide variety of countries in the world demonstrate, the scope of a promoter position may become limited by social and societal separation, antagonism, contempt and hate. Individuals or groups may embrace a Hitler or a hate-imam in their hearts or adore a Machiavellian type of leader who promises to solve complex problems with simplifying and misleading slogans in times of uncertainty (Hermans and Dimaggio 2007), insecurity (Kinnvall 2004), and risk (Beck 2002). Such individuals or groups may develop impoverished promoter positions as motivational forces to act on the basis of self-other antagonisms with a simultaneous seclusion of the human level of functioning. Over the course of human history, the unfamiliar and strange evoke strong emotions such as fear, aggression, hate, aversion, and expulsion. As Merskin (2004) has argued, xenophobic and racist sentiments create an artificial binary opposition between in-groups and out-groups that leads to the devaluation or even physical annihilation of one side by the other. The resultant 'we versus them' dichotomy produces forms of 'group think' and leads to enemy image construction which supports and confirms separation or marginalization of racial, religious, ethnic, or cultural communities, positioning them as hostile (Kinnvall 2004). On the contrary, moving towards more encompassing levels of inclusiveness, to the human and even, as proposed by Haslam et al. (2000), to the animal level, may 
facilitate the development of promoter positions that motivate actions that go beyond ego-centrism, group-centrism, ethno-centrism and even human-centrism.

\section{Research Questions}

The presented model allows a series of research questions. We limit ourselves to those questions which we consider most relevant to future studies on the democratic self.

Moving between Self and Other Central to the proposed model is the assumption that moving between self- and other-positions may evoke new positions at their interface that will enhance social compassion and understanding. Although this link has been extensively discussed in the present article (multicultural, multiracial, transgender identities), the question remains under which conditions individuals and groups are able and willing to flexibly move between self- and other positions. Which factors facilitate or obstruct this process? Will these movements trigger the construction of positions at the interface of self and other (e.g., friendship or cooperation across cultural or racial boundaries)? And will merely taking these positions enhance the ability and willingness to give freedom of expression and care to positions of other individuals or groups which are different from one's own?

Moving between Levels of Inclusiveness Equally central to the model is the argument that flexible movements between levels of inclusiveness may evoke adaptive $I$-positions in fields of tension. Under which conditions are individuals or groups able and willing to make flexible movements from the individual or social level (e.g., cultural, racial, ethnic, or gender positions) to the human level of inclusiveness and vice versa? Which factors function as obstacles to making these movements? If these movements are made, will they instigate new positions at the interface of these levels (e.g. membership of local groups with a humanizing mission) and under which conditions? And how will positions at the interface of the levels combine self-esteem derived from personal distinctiveness or ingroup favoritism (relevant to the democratic ideal of freedom) with empathy and care derived from the human level (relevant to the democratic ideal of equality)?

Meta-Positions We argued that meta-positions are needed for shielding the self from fragmentation and for taking a broad picture view. What are the characteristics of metapositions that allow individuals to have access to $I$-positions located in fields of tensions (e.g., multi-cultural, multi-racial, multi-gender)? Under which conditions is the bandwidth of the position repertoire (i.e., the number and variety of $I$-positions subjected to self-reflection and dialogue) widened or restricted? Do specific positions (e.g., unwanted, rejected ones) need to be accessible from the perspective of a meta-position in order to maintain a coherent yet flexible organization?

Promoter Positions We argued that promoter positions might help to push the position repertoire into a democratic direction. However, we also concluded that powerrelationships might dominate over dialogical ones. Is it possible to develop democratic promoter positions in fields of tension between cultural, racial, ethnic, or gender positions that are strong enough to have a boundary-crossing impact (e.g., membership 
of international organizations for the improvement of the situation of LGTB people, or improving the situation of black or colored people in predominantly white institutions)? What is needed to be able to construct 'promoters of care' transcending ingroupoutgroup boundaries and transcending different levels of inclusiveness? Is this possible while maintaining a balance between both self-esteem and care for the other?

Coping with Uncertainty Do upward and downward movements between levels of inclusiveness and between self and other positions initially or chronically result in increasing amounts of uncertainty or feelings of 'identity loss?' Does 'tolerance of uncertainty' mediate the transition from the personal or social level to the human level and does it create space for positions of the other which are different from one's own? Does the fostering of trust, considered, by Marková and Gillespie (2008) as a necessary condition for the emergence of dialogical relationships, facilitate this tolerance?

Self and Society As we have proposed in this article, individual I-positions and their mutual constellation are necessarily embedded within I-positions of other individuals and groups. An important question therefore is how organizations can facilitate the hence and forth movements between positions of ingroups and outgroups and between different levels of inclusiveness. Will it suffice to include democratic principles (freedom, equality, and care on a global level) top-down in their purposes and missions, or will a critical mass of individuals with a democratic organization of their selves be needed to encourage individuals and groups to transcend separating boundaries between one's own cultural, racial, ethnic, religious, and gender positions and those of other groups? How can organizations instigate differentiation between personal, social, and global responsibility and stimulate each of them? Which actions or features will foster and enhance the development of a sense of global consciousness in their members?

\section{Conclusion}

Models of the self as a totalitarian state and as a hierarchical bureaucratic organization are, by their top-down communication lines, well equipped for efficient decision making. As highly centralized structures, they resonate with notions of a bounded, sovereign self with sharp boundaries between self and non-self. In contrast to this view, classic theorist like James, Mead, Bakhtin, Buber, and Heidegger, have presented arguments for the extended nature of the self with the other as its constituting part. In line with these thinkers, we propose a democratic society as a metaphor for the self that requires bottom-up communication lines and contributions from a diversity of agreeing, disagreeing, and opposing points of view. Continuously involved in processes of positioning and counter-positioning between internal $I$-positions and positions of (powerful) others in the extended self, fields of tensions emerge beyond the limiting boundaries of binary and separating social classifications. As a test-case for the fertility of the democratic metaphor, we referred to literature on multi-cultural, multi-racial, and transgender identities and showed that fields of tension, emerging between the binaries, 
function as 'third spaces' for the construction of hybrid and new forms of identity. These fields imply both opportunities (e.g., flexibility of adaptation, improved psychological health, enhanced creativity) and risks (e.g., identity confusion, health problems, loss of self-esteem) for the development of the self.

We used the discussion of cultural, racial, and gender identities as a stepping stone for placing the self in the broader context of models of a deliberative, cosmopolitan, and agonistic democracy as these forms of democracy require the dialogical capacities of individuals and groups who are crossing the boundaries of cultural, ethnic, racial, and gender dualities. At that point we proposed a 'crossover' between psychological theories of social identity and self-categorization on the one hand and political model of cosmopolitan democracy, with attention to both deliberation and social power, on the other hand. We argued that a democratically functioning self allows for movements not only between self and other as its extension, but also between different levels of inclusiveness (personal, social, human). We presented a model in which the inclusion of the human level is corresponding with proposals of a cosmopolitan democracy in a globalizing society.

Acknowledgment We thank Reineke Lengelle for her detailed editorial comments.

Compliance with Ethical Standards The authors declare that they comply with the ethical standards of the Journal.

There are no conflicts of interest, no human or animal subjects were involved and informed consent is not applicable.

Open Access This article is distributed under the terms of the Creative Commons Attribution 4.0 International License (http://creativecommons.org/licenses/by/4.0/), which permits unrestricted use, distribution, and reproduction in any medium, provided you give appropriate credit to the original author(s) and the source, provide a link to the Creative Commons license, and indicate if changes were made.

\section{References}

American Psychiatric Association (2013a). Diagnostic and Statistical Manual of Mental Disorders, fifth edition (DSM-5). Washington, DC: American Psychiatric Association.

American Psychiatric Association (2013b). Gender dysphoria. http://www.dsm5.org/documents/gender\%20 dysphoria\%20fact $\% 20$ sheet.pdf.

Andersen, S. M., \& Chen, S. (2002). The relational self: an interpersonal social-cognitive theory. Psychological Bulletin, 109, 619-645.

Appadurai, A. (1990). Disjuncture and difference in the global cultural economy. In M. Featherstone (Ed.), Global culture: nationalism, globalization and modernity (pp. 295-310). London: Sage.

Archibugi, D. (2004). Cosmopolitan democracy and its critics: a review. European Journal of International Relations, 10, 437-473.

Aristotle (1954). Ethica Nicomachea (trans. R. W. Thuijs). Antwerp: De Nederlandse Boekhandel.

Arnett, J. (2002). The psychology of globalization. American Psychologist, 57, 774-783.

Aron, A., Mashek, D., McLaughlin-Volpe, T., Wright, S., Lewandowski, G., \& Aron, E. (2005). Including close others in the cognitive structure of the self. In M. Baldwin (Ed.), Interpersonal cognition (pp. 206232). New York: Guilford Press.

Bakhtin, M. (1984). Problems of Dostoevsky's poetics. (C. Emerson, Ed. And trans). Minneapolis: University of Minnesota Press.

Baldwin, M. W. (2002). Relational schemas and the processing of social information. Psychological Bulletin, $112,461-484$. 
Bamberg, M., \& Andrews, M. (2004). Considering counter-narratives: narrating, resisting, making sense. Amsterdam: John Benjamins.

Beck, U. (2002). The terrorist threat: world risk society revisited. Theory, Culture \& Society, 19, 39-55.

Berry, J. W. (1997). Immigration, acculturation and adaptation. Applied Psychology: An International Review, $46,5-68$.

Bhatia, S. (2007). American karma: race, culture, and identity in the Indian diaspora. New York: New York University Press.

Bilodeau, K., \& Renn, K. A. (2005). Analysis of LGBT identity development models and implications for practice. New Directions for Student Services, 111, 25-39.

Binning, K. R., Unzueta, M. M., Huo, Y. J., \& Molina, L. E. (1999). The interpretation of multiracial status and its relation to social engagement. Journal of Social Issues, 65, 35-49.

Blattberg, C. (2003). Patriotic, not deliberative, democracy. Critical Review of International Social and Political Philosophy, 6, 155-174.

Bondi, L. (2004). Tenth anniversary address: for a feminist geography of ambivalence. Gender, Place and Culture, $11,3-15$.

Bornstein, K. (1994). Gender outlaw: on women, men, and the rest of us. New York: Routledge.

Branco, A. U., Branco, A. L., \& Madureira, A. F. (2008). Self-development and the emergence of new I positions: emotions and self-dynamics. Studia Psychologica, 6, 23-39.

Brewer, M. B. (1991). The social self: on being the same and different at the same time. Personality and Social Psychology Bulletin, 17, 475-482.

Browne, K., Nash, C. J., \& Hines, S. (2010). Introduction: towards trans geographies. Gender, Place and Culture, 17, 573-577.

Buber, M. (1970). I and Thou. A new translation with a prologue "I and you" and notes by Walter Kaufmann. Edinburgh: T. \& T. Clark.

Butler, J. (1990). Gender trouble: feminism and the subversion of identity. New York: Routledge.

Charny, I. W. (2006). Fascism and democracy in the human mind. Lincoln: University of Nebraska Press.

Cheng, C. Y., Sanchez-Burks, J., \& Lee, F. (2008). Connecting the dots within: creative performance and identity integration. Psychological Science, 19, 1178-1184.

Crocker, J., \& Luhtanen, R. (1990). Collective self-esteem and ingroup bias. Journal of Personality and Social Psychology, 58, 60-67.

Cruikshank, B. (1999). The will to empower: democratic citizens and other subjects. New York: Cornell University Press.

Davidson, M. (2007). Seeking refuge under the umbrella: inclusion, exclusion, and organizing within the category transgender. Sexual Research and Social Policy, 4, 60-80.

Davies, B. \& Harré, R. (2007). Positioning: the discursive production of selves. Article in Journal for the Theory of Social Behavior. Available from: Rom Harré, retrieved on: 14 July 2015.

Doan, P. L. (2010). The tyranny of gendered spaces: reflections from beyond the gender dichotomy. Gender, Place \& Culture: A Journal of Feminist Geography, 17, 635-654.

Dunne, J. (1996). Beyond sovereignty and deconstruction: the storied self. Philosophy and Social Criticism, $21,137-157$.

Fishkin, J. (1991). Democracy and deliberation: new directions for democratic reform. New Haven: Yale University Press.

Flavell, J. H. (1979). Metacognition and cognitive monitoring: a new area of cognitive-developmental inquiry. American Psychologist, 34, 906-911.

Geertz, C. (1979). From the native's point of view: on the nature of anthropological understanding. In P. Rabinow \& W. M. Sullivan (Eds.), Interpretive social science (pp. 225-241). Berkeley: University of California Press.

Gergen, K. (2009). Relational being: beyond self and community. New York: Oxford University Press.

Giddens, A. (1990). The consequences of modernity. Cambridge: Polity.

Greenwald, A. G. (1980). The totalitarian ego: fabrication and revision of personal history. American Psychologist, 35, 603-618.

Grossman, A. H., Augelli, A. R., Howell, T. J., \& Hubbard, S. (2005). Parents' reactions to transgender youths' gender nonconforming expression and identity. Journal of Gay \& Lesbian Social Services, 18, 316.

Hall, S. (1994). Cultural identity and diaspora. In P. Williams \& L. Chrisman (Eds.), Colonial discourse and post-colonial theory: a reader (pp. 392-403). New York: Columbia University Press.

Haslam, S. A., Powell, C., \& Turner, J. C. (2000). Social identity, self-categorization, and work motivation: rethinking the contribution of the group to positive and sustainable organisational outcomes. Applied Psychology: An International Review, 49, 319-339. 
Heidegger, M. (1996). Being and time: a translation of Sein und Zeit. Albany: State University of New York Press.

Hermans, H. J. M. (2015). Human development in today's globalizing world: implications for self and identity. In L. Arnett Jensen (Ed.), The Oxford handbook of human development and culture (pp. 28-42). New York: Oxford University Press.

Hermans, H. J. M. (2017). Society in the self: a theory of identity in democracy. New York: Oxford University Press.

Hermans, H. J. M., \& Dimaggio, G. (2007). Self, identity, and globalization in times of uncertainty: a dialogical analysis. Review of General Psychology, 11, 31-61.

Hermans, H. J. M., \& Gieser, T. (2012). Handbook of dialogical self theory. Cambridge: Cambridge University Press.

Hermans, H. J. M., \& Hermans-Konopka, A. (2010). Dialogical self theory: positioning and counterpositioning in a globalizing society. Cambridge: Cambridge University Press.

Higgins, E. T. (1987). Self-discrepancy; a theory relating self and affect. Psychological Review, 94, 319-340.

Hogg, M. A., \& Terry, D. I. (2000). Social identity and self-categorization processes in organizational contexts. Academy of Management Review, 25, 121-140.

Hornsey, M. J. (2008). Social identity theory and self-categorization theory: a historical review. Social and Personality Psychology Compass, 2, 204-222.

Huddy, L. (2001). From social to political identity: a critical examination of social identity theory. Political Psychology, 22, 127-156.

Hughto, J. M. W., Reisner, S. L., \& Pachankis, J. E. (2015). Transgender stigma and health: a critical review of stigma determinants, mechanisms, and interventions. Social Science \& Medicine, 147, 222-231.

Hussain, D. (2015). Meta-cognition in mindfulness: a conceptual analysis. Psychological Thought, 8, 132141.

James, W. (1890). The principles of psychology (Vol. 1). London: Macmillan.

Jones, V. A. (2015). The black-white dichotomy of race: influence of a predominantly white environment on multiracial identity. Higher Education in Review, 12, 1-22.

Kapchan, D. Z., \& Strong, P. T. (1999). Theorizing the hybrid. Journal of American Folklore, 112, $239-225$.

Kazaleh, F. A. (1986). Biculturalism and adjustment: A study of Ramallah-American adolescents in Jacksonville, Florida. Dissertation Abstracts International, 47, 448A. (University Microfilms No. DA 8609672).

Kinnvall, C. (2004). Globalization and religious nationalism: self, identity, and the search for ontological security. Political Psychology, 25, 741-767.

König, J. (2009). Moving experience: dialogues between personal cultural positions. Culture and Psychology, $15,97-119$.

Konik, J., \& Crawford, M. (2004). Exploring normative creativity: testing the relationship between cognitive flexibility and sexual identity. Sex Roles, 51, 249-253.

LaFromboise, T., Coleman, H. L. K., \& Gerton, J. (1993). Psychological impact on biculturalism: evidence and theory. Psychological Bulletin, 114, 395-412.

Leung, A. K., \& Chiu, C.-Y. (2010). Multicultural experience, idea receptiveness, and creativity. Journal of Cross-Cultural Psychology, 41, 723-741.

Liu, J. H., \& Macdonald, M. (2016). Towards a psychology of global consciousness through an ethical conception of self in society. Journal for the Theory of Social Behaviour., 46, 310-334.

Luke, C., \& Luke, A. (1999). Theorizing interracial families and hybrid identity: an Australian perspective. Educational Theory, 49, 223-249.

Mandela, N. (2000). The challenge of the next century: the globalization of responsibility. New Perspectives Quarterly, 17, 34-35.

Marková, I., \& Gillespie, A. (Eds.) (2008). Trust and distrust: Sociocultural perspectives. Charlotte: Information Age Publishing.

Mead, G. H. (1934). Mind, self, and society. Chicago: University of Chicago Press.

Merskin, D. (2004). The construction of Arabs as enemies: post-September 11 discourse of George W. Bush. Mass Communication and Society, 7, 157-175.

Minsky, M. (1985). The society of mind. New York: Simon \& Schuster.

Morioka, M. (2015). How to create Ma-the living pause-in the landscape of the mind: the wisdom of Nohtheatre. International Journal for Dialogical Science, 9, 81-95.

Mouffe, C. (2000). Deliberative democracy or agonistic pluralism. In C. Neuhold \& G. Hafner (Eds.), Political science series 72 (pp. 1-17). Vienna: Institute for Higher Studies.

Nestle, J., Howell, C., \& Wilchins, R. (Eds.) (2002). Genderqueer: voices from beyond the sexual binary. Los Angeles: Alyson Publications. 
O’Sullivan-Lago, R., \& de Abreu, G. (2010). Maintaining continuity in a cultural contact zone: identification strategies in the dialogical self. Culture \& Psychology, 16, 73-92.

Offe, C., \& Preuss, U. (1991). Democratic institutions and moral resources. In D. Held (Ed.), Political theory today (pp. 143-171). Cambridge: Polity.

Ogilvie, D. M., \& Ashmore, R. D. (1991). Self-with-other representation as a unit of analysis in self-concept research. In R. C. Curtis (Ed.), The relational self: theoretical convergencies in psychoanalysis and social psychology (pp. 282-314). New York: Guilford Press.

Oosterwegel, A., \& Oppenheimer, L. (1993). The self-system: developmental changes between and within selfconcepts. Hillsdale: Lawrence Erlbaum.

Richardson, F. C., \& Woolfolk, R. L. (2013). Subjectivity and strong relationality. In R. W. Tafarodi (Ed.), Subjectivity in the twenty-first century: psychological, sociological, and political perspectives (pp. 1140). Cambridge: Cambridge University Press.

Rockquemore, K. A., Brunsma, D. L., \& Delgado, D. J. (2009). Understanding the struggle to build a multiracial identity theory. Journal of Social Issues, 65, 13-34.

Rosenberg, M. (1979). Conceiving the self. New York: Basic Books.

Rosenmann, A., Reese, G., \& Cameron, J. E. (2016). Social identities in a globalized world: challenges and opportunities for collective action. Perspectives on Psychological Science, 11, 202-221.

Sampson, E. (1985). The decentralization of identity: toward a revised concept of personal and social order. American Psychologist, 11, 1203-1211.

Sedikides, C., \& Brewer, M. B. (Eds.) (2001). Individual self, relational self, collective self. London: Routledge.

Sen, A. K. (1999). Democracy as a universal value. Journal of Democracy, 10, 3-17.

Shih, M., \& Sanchez, D. T. (2009). When race becomes even more complex: toward understanding the landscape of multiracial identity and experiences. Journal of Social Issues, 65, 1-11.

Simon, B., \& Klandermans, B. (2001). Politicized collective identity. American Psychologist, 56, 319-331.

Sindic, D., \& Condor, S. (2014). Social identity theory and self-categorization theory. In T. Capelos, C. Kinvall, P. Nesbitt-Larkin, \& H. Dekker (Eds.), The Palgrave handbook of global political psychology (pp. 39-54). New York: Palgrave.

Smith, K. E. I. (2008). Hybrid identities: theoretical examinations. In K. E. I. Smith \& P. Leavy (Eds.), Hybrid identities: theoretical and empirical examinations (pp. 3-12). Brill: Leiden.

Tajfel, H., \& Turner, J. C. (1979). An integrative theory of intergroup conflict. In W. G. Austin \& S. Worchel (Eds.), The social psychology of intergroup relations (pp. 33-47). Monterey: Brooks-Cole.

Townsend, S. S. M., Markus, H. R., \& Bergsieker, H. B. (2009). My choice, your categories: the denial of multiracial identities. Journal of Social Issues, 65, 183-202.

Turner, J. C., Hogg, M. A., Oakes, P. J., Reicher, S. D., \& Wetherell, M. S. (1987). Rediscovering the social group: a self-categorization theory. Oxford: Blackwell.

Valentine, D. (2007). Imagining transgender: an ethnography of a category. Durham: DukeUniversity Press.

Valsiner, J. (2005). Scaffolding within the structure of dialogical self: hierarchical dynamics of semiotic mediation. New Ideas in Psychology, 23, 197-206.

Van Loon, R., \& Van den Berg, T. (2016). Dialogical leadership: the 'other' way to coach leaders. In H. J. M. Hermans (Ed.), Assessing and stimulating a dialogical self in groups, teams, cultures, and organizations (pp. 75-93). New York: Springer.

Van Meijl, T. (2012). Multiculturalism, multiple identification and the dialogical self: shifting paradigms of personhood in sociocultural anthropology. In H. J. M. Hermans \& T. Gieser (Eds.), Handbook of dialogical self theory (pp. 98-114). Cambridge: Cambridge University Press.

Vaughan, M. D., \& Rodriguez, E. M. (2014). LGBT strengths: incorporating positive psychology into theory, research, training, and practice. Psychology of Sexual Orientation and Gender Diversity, 1, 325-334.

Wallace, C. S. (2004). Framing new research in science literacy and language use: authenticity, multiple discourses, and the "third space". Science Education, 88, 901-914.

Wohl, M. J. A., \& Branscombe, N. R. (2005). Forgiveness and collective guilt assignment to historical perpetrator groups depend on level of social category inclusiveness. Journal of Personality and Social Psychology, 88, 288-303. 